\title{
Large-scale studies of the $H p h$ insulin gene variable-number-of-tandem-repeats polymorphism in relation to Type 2 diabetes mellitus and insulin release
}

\author{
S. K. Hansen ${ }^{1}$ A. P. Gjesing ${ }^{1}$ S. K. Rasmussen ${ }^{1}$ C. Glümer ${ }^{1,2}$ • S. A. Urhammer ${ }^{1}$ G. Andersen ${ }^{1}$ • \\ C. S. Rose $^{1}$ - T. Drivsholm ${ }^{2}$ S. K. Torekov ${ }^{1}$ D. P. Jensen ${ }^{1}$ C C. T. Ekstrøm ${ }^{1}$ - K. Borch-Johnsen ${ }^{1,2,3}$ • \\ T. Jørgensen ${ }^{2} \cdot$ M. I. McCarthy ${ }^{4}$ T. Hansen 1 - O. Pedersen ${ }^{1,3}$ \\ ${ }^{1}$ Steno Diabetes Center and Hagedorn Research Institute, Gentofte, Denmark \\ ${ }^{2}$ Research Center for Prevention and Health, Copenhagen County, Glostrup University Hospital, Glostrup, Denmark \\ ${ }^{3}$ Faculty of Health Science, University of Aarhus, Aarhus, Denmark \\ ${ }^{4}$ Oxford Centre for Diabetes, Endocrinology and Metabolism, University of Oxford, Oxford, UK
}

\section{Abstract}

Aims/hypothesis. The class III allele of the variablenumber-of-tandem-repeats polymorphism located $5^{\prime}$ of the insulin gene (INS-VNTR) has been associated with Type 2 diabetes and altered birthweight. It has also been suggested, although inconsistently, that the class III allele plays a role in glucose-induced insulin response among NGT individuals.

Methods. We investigated the impact of the class III allele on Type 2 diabetes susceptibility in a case-control study involving 1462 Type 2 diabetic patients and 4931 NGT subjects. We also examined the potential impact of the class III allele in genotype-quantitative trait studies in three Danish study populations containing (i) 358 young healthy subjects; (ii) 4444 middleaged NGT subjects, 490 subjects with IFG and 678 subjects with IGT; and (iii) 221 NGT subjects, of whom one parent had Type 2 diabetes.
Results. There was no difference in frequency of the class III allele or in genotype distribution between the 1462 Type 2 diabetic patients and the 4931 NGT subjects. Among the 358 young subjects the class III/III carriers had significantly reduced post-IVGTT acute serum insulin and C-peptide responses $(p=0.04$ and 0.03 respectively). However, among the 4444 middleaged subjects we failed to demonstrate any association between the class III allele and post-OGTT serum insulin and C-peptide levels.

Conclusions/interpretation. The class III allele of the INS-VNTR does not confer susceptibility to Type 2 diabetes or consistent alterations in glucose-induced insulin release in the examined populations, which consisted of Danish Caucasians.

Keywords Altered birthweight $\cdot H p h \mathrm{I}$ insulin gene variable-number-of-tandem-repeats (INS-VNTR) polymorphism - Insulin release - Type 2 diabetes.
Received: 9 February 2004 / Accepted: 17 March 2004

Published online: 29 May 2004

(C) Springer-Verlag 2004

S. K. Hansen (

Steno Diabetes Center and Hagedorn Research Institute,

Niels Steensens Vej 2, 2820 Gentofte, Denmark

E-mail: sakf@steno.dk

Tel.: +45-444437233, Fax: +45-444438232

Abbreviations: INS, insulin gene $\cdot$ HOMA IR, HOMA insulin resistance - HOMA IS, HOMA insulin secretion - OHA, oral hypoglycaemic agents $\cdot$ PCOS, polycystic ovary syndrome . $\mathrm{S}_{\mathrm{i}}$, insulin sensitivity index $\cdot \mathrm{SNP}$, single nucleotide polymorphism VNTR, variable number of tandem repeats

\section{Introduction}

The variable-number-of-tandem-repeats (VNTR) region located in the proximal promoter, $596 \mathrm{bp}$ from the translational start site, of the insulin gene (INS) is composed of tandemly repeated sequences of $14-15 \mathrm{bp}$ and falls into three size classes. The class $I$ (26-63 repeats) and the class III (141-209 repeats) alleles have reported frequencies among Caucasians of between $0.67-0.72$ and $0.28-0.33$ respectively, while the intermediary class $I I$ (64-140 repeats) allele is rare among Caucasians $[1,2,3]$.

The INS-VNTR influences insulin expression in vitro $[4,5]$, and in vivo the class $I I I$ allele is reportedly associated with decreased levels of insulin mRNA in the pancreas $[6,7]$. In addition, the INS-VNTR affects $I G F-2$ transcription in human placenta [8]. 
The INS-VNTR may also be implicated in several human disorders, including polycystic ovary syndrome (PCOS) [9] and Type 1 diabetes [1], and several lines of evidence indicate that it may also confer an increased susceptibility to Type 2 diabetes.

Firstly, a meta-analysis combining six small casecontrol studies published up to 1990 and focusing on different Caucasian populations showed an association between the INS-VNTR class III/III genotype and Type 2 diabetes. These studies involved a total of 392 Type 2 diabetic patients and 368 non-diabetic subjects. One study was excluded from the combined analysis, which then included five studies comprising 261 Type 2 diabetic patients and 286 non-diabetic subjects. The combined analysis showed a relative risk of contracting Type 2 diabetes of $1.86(p=0.03)$ for the class III/III carriers [1]. Furthermore, a recent study involving 155 parent-offspring trios reported an association between Type 2 diabetes and the INSVNTR class III allele, but only when the class III allele was paternally inherited [10]. Secondly, an association between the class III allele and PCOS, a disease characterised by hyperinsulinaemia and insulin resistance, has been described [9]. Thirdly, an association between the class III allele and impaired insulin secretion among healthy subjects has been reported [11]. Fourthly, variation of the INS-VNTR has been associated with increased and decreased birthweight $[12,13]$. And finally, it has been suggested, in a study of obese children [2], that variation of the INS-VNTR affects fasting serum insulin levels, while a recent study reported an effect of the class III allele on increased BMI and decreased insulin sensitivity in three Caucasian cohorts comprising a total of 1184 children and 1099 parents [3].

These findings suggest that the INS-VNTR may be implicated in insulin-regulated intrauterine growth and insulin secretion in adults, and thus could partly explain the reported association between low birthweight and Type 2 diabetes [14].

In the present study we have examined variation of the INS-VNTR in relation to Type 2 diabetes, insulin release, size at birth, and a potential parent-of-origin effect using the following study populations: (i) 1462 Type 2 diabetic patients and 4931 NGT control subjects (case-control study); (ii) a population-based sample of 358 young healthy subjects; (iii) a population-based sample comprising 4444 middle-aged NGT individuals, 490 individuals with IFG, and 678 individuals with IGT; and (iv) a study population of 221 NGT offspring, of whom one parent had Type 2 diabetes (study of parent-of-origin effect). Among Caucasians the -23 HphI SNP is in tight linkage disequilibrium with the INS-VNTR class $I$ and class III alleles (99.7\% concordance) [1]. Therefore, we used genotyping of the $-23 \mathrm{HphI}$ SNP as an indirect subtyping of the INS-VNTR class $I$ and class $I I I$ alleles.

\section{Subjects and methods}

Subjects. For the case-control study 1462 Type 2 diabetic patients were recruited from the outpatient clinics in the greater Copenhagen area between 1992 and 2001 (1097 patients) and from the population-based Inter99 study performed at the Research Centre for Prevention and Health between 1999 and 2001 (365 patients). The patients (61\% men, 39\% women) had a mean age of 56.8 years $( \pm$ SD: 10.5 years $)$, BMI of $29.6 \mathrm{~kg} / \mathrm{m}^{2}\left( \pm 5.3 \mathrm{~kg} / \mathrm{m}^{2}\right), \mathrm{HbA}_{1} \mathrm{c}$ of $7.8 \%( \pm 1.7 \%)$ and an average duration of diabetes of 6.8 years $( \pm 6.7$ years $)$. Of these patients $51 \%$ were treated with diet alone, $35 \%$ with oral hypoglycaemic agents (OHA), 11\% with insulin and $3 \%$ received a combination of insulin and OHA. Diabetes was diagnosed in accordance with the World Health Organization (WHO) 1999 criteria. The NGT control subjects comprised 487 persons recruited through the Danish Central Population Register and Research Centre for Prevention and Health [15] and 4444 individuals recruited from the population-based Inter99 study. These people had the following characteristics: $46 \%$ men, $54 \%$ women; age (mean \pm SD): 46.3 years ( \pm 8.8 years); BMI: $25.5 \mathrm{~kg} / \mathrm{m}^{2}\left( \pm 4.1 \mathrm{~kg} / \mathrm{m}^{2}\right)$. The Inter99 study has been described in detail previously [16]. All control subjects were subjected to a WHO standard OGTT under fasting conditions and only subjects with NGT were included in the control group.

We did genotype-quantitative trait interaction studies in two Danish study populations. The first consisted of 4444 middleaged NGT subjects, 490 subjects with IFG and 678 subjects with IGT, all of whom were from the Inter99 study and were examined by a standard 75-g OGTT with measurements of circulating levels of glucose, insulin and C-peptide at 0,30 and $120 \mathrm{~min}$. The second was a population-based sample of 358 young healthy subjects, who underwent a tolbutamide-modified IVGTT for measurements of the acute serum insulin and C-peptide responses as described previously [17]. Data on birth length and birthweight of the latter group were obtained from the midwife records stored in the Danish Provincial Archives for Zealand, Lolland-Falster and Bornholm.

A study of parent-of-origin effect was performed in a population of 221 NGT offspring, of whom one parent had Type 2 diabetes. This group was from 62 families recruited from the Danish Family Resource Bank at the Department of Human Genetics, University of Copenhagen and from the outpatient clinic at Steno Diabetes Center [18].

All participants were Danish Caucasians by self-report. Informed consent was obtained from all study participants prior to participation. The studies were approved by the ethics committee of Copenhagen and were in accordance with the principles of the Declaration of Helsinki II.

Biochemical assays. Blood samples for measurements of fasting plasma glucose, serum insulin and serum C-peptide were drawn after a 12-hour overnight fast. All IVGTTs and OGTTs were performed in the morning in the fasting state. Plasma glucose was analysed by a glucose oxidase method (Granutest, Merck, Darmstadt, Germany) and serum-specific insulin (excluding des(31, 32)- and intact proinsulin) was measured using the AutoDELFIA insulin kit (Perkin Elmer, Wallac, Turku, Finland). The concentration of serum C-peptide was determined by a time-resolved fluoroimmunoassay with the AutoDELFIA C-peptide kit.

Genotyping of the INS-VNTR class I and class III alleles. The INS gene is very polymorphic with approximately 20 known haplotypes among Caucasians [19]. In this study we genotyped the $-23 H p h I$ SNP, which is an indirect subtyping of the INS- 
VNTR class $I$ and class $I I I$ alleles. We have thus only stratified the participants according to one SNP out of more than 20 known Caucasoid SNPs in the region spanning the INS gene [19].

DNA from 487 of the NGT control subjects, the 358 young healthy subjects and the 221 NGT offspring of whom one parent had Type 2 diabetes was genotyped using an HphI restriction enzyme digestion of PCR products obtained with the forward primer 5'-AGCAGGTCTGTTCCAAGG-3' and the reverse primer $5^{\prime}$-CTTGGGTGTGTAGAAGAAGC-3', followed by agarose electrophoresis of the digested PCR products, as previously reported [7]. The remaining samples were genotyped for the $-23 H p h$ I SNP applying a method based on mass spectrometry as described [20]. The genotyping success rates of the RFLP-based method and the mass-spectrometry-based method were $93 \%$ and $98 \%$ respectively. To elucidate the genotyping error rate we examined 88 replicate samples, but found no mismatches.

Statistical analysis. Acute serum insulin and serum C-peptide responses during a tolbutamide-modified IVGTT were calculated as the incremental area under the insulin/C-peptide curve for 0 to $8 \mathrm{~min}[17,18]$. The insulin sensitivity index $\left(\mathrm{S}_{\mathrm{i}}\right)$ was measured using Bergman's minimal model on data obtained during the IVGTT. The disposition index was calculated as: acute insulin response IVGTT $_{\text {IVT }} \times \mathrm{S}_{\mathrm{i}}$; the insulinogenic index for insulin or C-peptide was calculated as: (insulin/C-peptide at 30 minutes - fasting insulin/C-peptide)/glucose at 30 minutes; the incremental AUCs for glucose, insulin and C-peptide from 0 to 120 minutes were calculated using the trapezoidal method. HOMA insulin resistance (HOMA IR) was calculated as (fasting plasma glucose $\times$ fasting serum insulin)/22.5; HOMA insulin secretion (HOMA IS) was calculated as $20 \times$ fasting serum insulin/(fasting plasma glucose -3.5 ). The ponderal index was calculated as birthweight/(birth length) ${ }^{3}$.

Differences in allelic frequencies were analysed by a Fisher's exact test using the Web-Assotest program (available at: http://www.ekstroem.com/assotest/assotest.html), and differences in genotype distribution among Type 2 diabetic patients and control subjects were analysed using logistic regression with adjustments for age and sex. All genotype distributions were tested for Hardy-Weinberg equilibrium using a likelihood ratio test.

Differences in continuous variables were tested using a general linear model for analysis of variance with adjustments for age, sex and BMI. All residuals were tested for normal distribution, and transformation (ln- or cube root transformation) of the variables was made if necessary.

The parent-of-origin effect was studied by comparing subjects carrying one paternally transmitted class $I I I$ allele with subjects carrying one maternally transmitted class III allele using a variance component model with genotype, sex, age and $\mathrm{BMI}$ as explanatory variables and familial structure as a random factor.

The Statistical Package for Social Science (SPSS) for Windows (version 11.5) or the SAS System for Windows 8.02 were used for statistical analysis. A $p$ value of less than 0.05 was considered significant.

\section{Results}

The case-control study showed no significant difference in allelic frequencies or genotype distribution of the $-23 H p h I$ polymorphism, among 1462 unrelated Type 2 diabetic patients (allelic frequency of the $t$ allele [class III allele]: $29.1 \%$ [95\% CI: 27.4-30.7\%]), as compared with the 4931 unrelated glucose-tolerant subjects $(28.3 \%, 95 \%$ CI: 27.5-29.2\%) (Table 1). The genotype distributions were in Hardy-Weinberg equilibrium. When using a selected subgroup comprising only 1454 age- and sex-matched NGT subjects from the total group of 4931 control subjects, there was still no significant difference in allelic frequency or genotype distribution between diabetic patients and control subjects (748 class $I$ homozygotes, 587 heterozygotes and 119 class III homozygotes, allelic frequency: $28.4 \%$, 95\% CI: $26.7-30.0 \%$ for the 1454 control subjects).

Analyses were also performed stratifying both groups on sex and BMI below or above the median value respectively, and cases of diabetes on clinical diabetes onset before or after the age of 45 years. However, no significant associations between genotype distribution and subsets of Type 2 diabetes were found (data not shown). To exclude the possibility of bias in selection of the Type 2 diabetic patients and control subjects, we made a case-control study comprising only the 365 Type 2 diabetic patients and the 4444 NGT control subjects from the population-based Inter99 study. However, there was no significant difference in allelic frequency of the class III allele or genotype distribution (Type 2 diabetic patients: 188 class I homozygotes, 142 heterozygotes, 35 class III

Table 1. Case-control study of the INS-VNTR (-23 HphI polymorphism) comprising 1462 Type 2 diabetic patients and 4931 glucosetolerant subjects

\begin{tabular}{|c|c|c|c|c|c|c|c|c|}
\hline & $\begin{array}{l}a a \\
\text { Class I/I } \\
(\%)\end{array}$ & $\begin{array}{l}\text { at } \\
\text { Class I/III } \\
(\%)\end{array}$ & $\begin{array}{l}t t \\
\text { Class III/III } \\
(\%)\end{array}$ & $p$-MAF & $p$-add & $p$-add ${ }^{\mathrm{a}}$ & $p$-rec ${ }^{\mathrm{a}}$ & $p$-doma \\
\hline $\begin{array}{l}\text { Type } 2 \text { diabetic patients } \\
\text { MAF: } 29.1 \% \text { (95\% CI: } 27.4-30.7 \%)\end{array}$ & $\begin{array}{l}738 \\
(50)\end{array}$ & $\begin{array}{l}598 \\
(41)\end{array}$ & $\begin{array}{l}126 \\
(9)\end{array}$ & & & & & \\
\hline $\begin{array}{l}\text { NGT participants } \\
\text { MAF: } 28.3 \% \text { (95\% CI: } 27.5-29.2 \%)\end{array}$ & $\begin{array}{l}2536 \\
(51)\end{array}$ & $\begin{array}{l}1995 \\
(41)\end{array}$ & $\begin{array}{l}400 \\
(8)\end{array}$ & 0.45 & 0.74 & 0.71 & 0.53 & 0.75 \\
\hline
\end{tabular}

The $p$ values represent tests for differences in genotype distribution or minor allele frequency (MAF) (95\% CI); $p$-MAF: $p$ value for difference in MAF; $p$-add, $p$-rec and $p$-dom: $p$ val- ues for differences in genotype distribution using an additive, a recessive and a dominant model respectively; a adjusted for age and sex 
Table 2. Clinical and biochemical data of 358 young healthy Danish Caucasians stratified according to the INS-VNTR class $I$ and class III alleles (-23 HphI polymorphism)

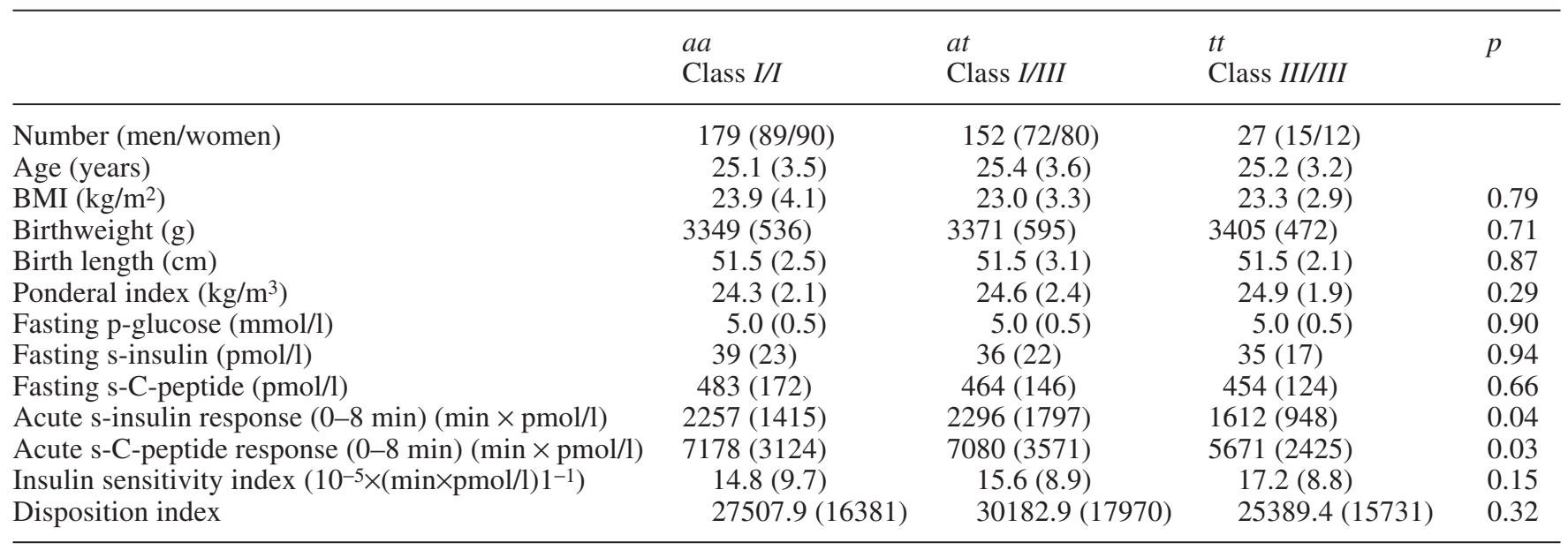

Data are means (SD) unless otherwise stated; $p$ values were obtained using a general linear model (SPSS) with age and BMI as covariates, and sex and genotype as fixed factors on vari- ables or transformed variables. BMI and age were excluded from the model when analysing birth data. p-glucose, plasma glucose; s-C-peptide, serum C-peptide; s-insulin, serum insulin
Table 3. Clinical and biochemical characteristics of 4444 NGT Danish Caucasian participants from the Inter99 cohort stratified according to the INS-VNTR class $I$ and class $I I I$ alleles
(-23 HphI polymorphism) and analysed applying an additive, a recessive and a dominant model

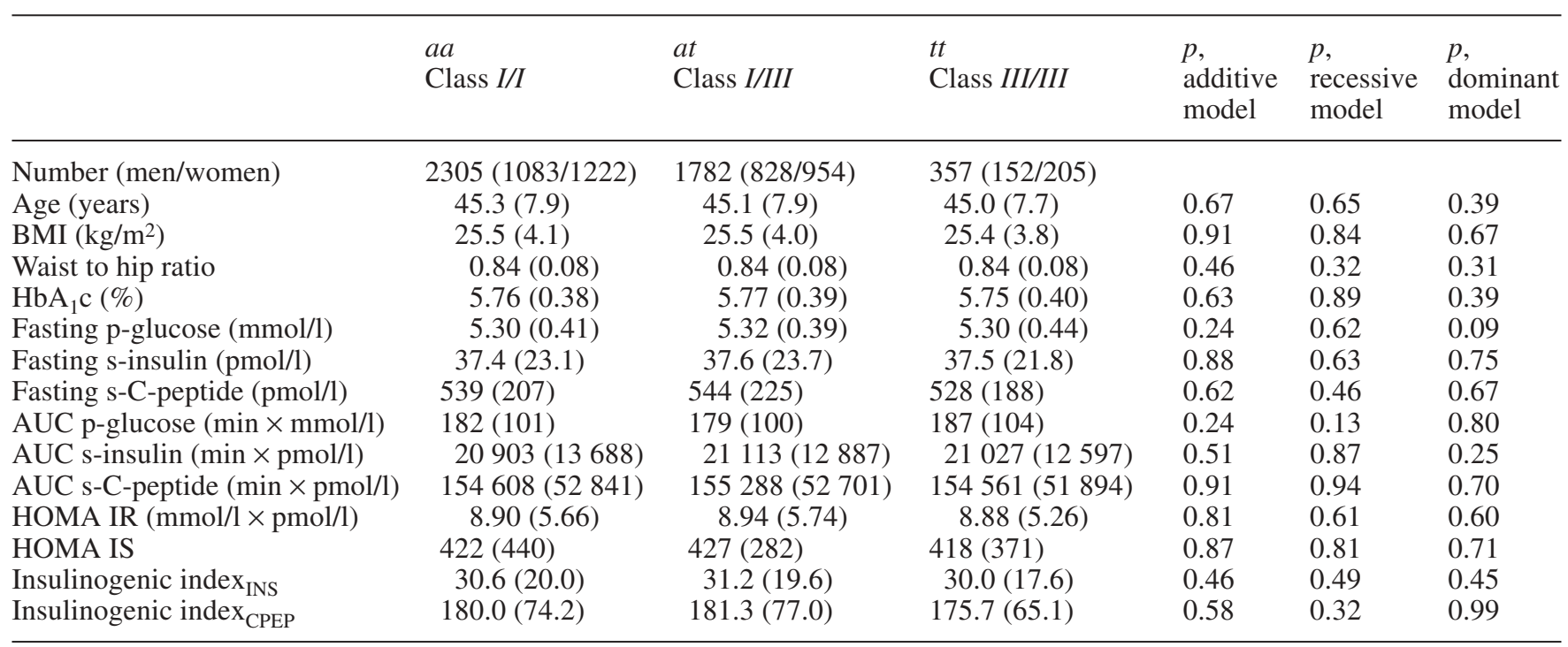

Data are means (SD), unless otherwise stated. $p$ values were obtained using a general linear model (SPSS) with age and BMI as covariates, and sex and genotype as fixed factors on variables or transformed variables. AUC, incremental area

homozygotes, allelic frequency: $29.0 \%, 95 \%$ CI: 25.7-32.3\%; NGT control subjects: 2305 class $I$ homozygotes, 1782 heterozygotes, 357 class III homozygotes, allelic frequency: $28.1 \%, 95 \% \mathrm{Cl}: 27.1-$ $29.0 \%$ ).

In genotype-quantitative trait studies among the 358 young healthy subjects, we observed that the class III/III carriers had a 20 to $30 \%$ decrease in acute serum insulin and C-peptide responses as estimated from an IVGTT when compared to wild-type and heterozygous carriers (recessive model) ( $p=0.04$ and 0.03 respective- under the curve (0-120 min) during the OGTT; HOMA IR, HOMA insulin resistance; HOMA IS, HOMA insulin secretion; p-glucose, plasma glucose; s-C-peptide, serum C-peptide; s-insulin, serum insulin

ly) (Table 2). No significant differences in birthweight or length, ponderal index or BMI were found between carriers and non-carriers of the class $I I I$ allele.

In the group of 4444 middle-aged NGT subjects we found no differences in post-OGTT insulin and C-peptide levels among carriers and non-carriers of the class III allele (Table 3). Estimates of insulin release (insulinogenic index for serum insulin and C-peptide) or measurements of BMI were not influenced by genotype either. We also analysed BMI and estimates of insulin release in 490 IFG subjects and 678 IGT sub- 
Table 4. The 490 participants with IFG from the Inter99 cohort, stratified according to the INS-VNTR class $I$ and class III alleles (-23 HphI polymorphism) and analysed using an additive, a recessive, and a dominant model

\begin{tabular}{|c|c|c|c|c|c|c|}
\hline & $\begin{array}{l}a a \\
\text { Class } I / I\end{array}$ & $\begin{array}{l}\text { at } \\
\text { Class } I / I I I\end{array}$ & $\stackrel{t t}{\text { Class } I I I / I I I}$ & $\begin{array}{l}p, \\
\text { additive } \\
\text { model }\end{array}$ & $\begin{array}{l}p, \\
\text { recessive } \\
\text { model }\end{array}$ & $\begin{array}{l}p, \\
\text { dominant } \\
\text { model }\end{array}$ \\
\hline Age (years) & $49.1(6.5)$ & $48.8(7.2)$ & $49.1(6.9)$ & 0.85 & 0.83 & 0.66 \\
\hline BMI $\left(\mathrm{kg} / \mathrm{m}^{2}\right)$ & $27.7(4.0)$ & $28.1(5.1)$ & $27.5(5.3)$ & 0.55 & 0.69 & 0.39 \\
\hline Waist to hip ratio & $0.90(0.08)$ & $0.90(0.08)$ & $0.90(0.08)$ & 0.80 & 0.50 & 0.89 \\
\hline Fasting s-insulin $(\mathrm{pmol} / \mathrm{l})$ & $50.0(26.9)$ & $50.9(30.5)$ & $48.2(23.1)$ & 0.86 & 0.99 & 0.59 \\
\hline Fasting s-C-peptide (pmol/l) & $737(313)$ & $722(297)$ & $674(260)$ & 0.32 & 0.37 & 0.16 \\
\hline AUC p-glucose $(\min \times \mathrm{mmol} / \mathrm{l})$ & $228(97)$ & $218(97)$ & $205(102)$ & 0.30 & 0.32 & 0.15 \\
\hline AUC s-insulin $(\min \times \mathrm{pmol} / \mathrm{l})$ & $23801(14929)$ & $23622(15428)$ & $21047(14179)$ & 0.59 & 0.42 & 0.40 \\
\hline AUC s-C-peptide $(\min \times \mathrm{pmol} / \mathrm{l})$ & $163443(58130)$ & $162789(52369)$ & $149655(43379)$ & 0.62 & 0.33 & 0.72 \\
\hline HOMA IR $(\mathrm{mmol} / \mathrm{l} \times \mathrm{pmol} / \mathrm{l})$ & $14.1(7.7)$ & $14.3(8.5)$ & $13.6(6.6)$ & 0.78 & 0.94 & 0.52 \\
\hline
\end{tabular}

Data are means (SD), unless otherwise stated. $p$ values were obtained using a general linear model (SPSS) with age and BMI as covariates, and sex and genotype as fixed factors on variables or transformed variables. AUC, incremental area under the curve (0-120 min) during the OGTT; HOMA IR, HOMA insulin resistance; HOMA IS, HOMA insulin secretion; p-glucose, plasma glucose; s-C-peptide, serum C-peptide; s-insulin, serum insulin

Table 5. The 678 participants with IGT from the Inter99 cohort, stratified according to the INS-VNTR class $I$ and class $I I I$ alleles (-23 HphI polymorphism) and analysed using an additive, a recessive, and a dominant model

\begin{tabular}{|c|c|c|c|c|c|c|}
\hline & $\begin{array}{l}a a \\
\text { Class } I / I\end{array}$ & $\begin{array}{l}\text { at } \\
\text { Class I/III }\end{array}$ & ${ }_{\text {Class } I I I / I I I}$ & $\begin{array}{l}p, \\
\text { additive } \\
\text { model }\end{array}$ & $\begin{array}{l}p, \\
\text { recessive } \\
\text { model }\end{array}$ & $\begin{array}{l}p, \\
\text { dominant } \\
\text { model }\end{array}$ \\
\hline Age (years) & $48.5(7.7)$ & $48.2(7.8)$ & $48.5(7.5)$ & 0.85 & 0.87 & 0.64 \\
\hline $\mathrm{BMI}\left(\mathrm{kg} / \mathrm{m}^{2}\right)$ & $28.0(5.2)$ & $28.3(5.1)$ & $28.2(5.4)$ & 0.84 & 0.87 & 0.56 \\
\hline Waist to hip ratio & $0.88(0.09)$ & $0.89(0.09)$ & $0.89(0.09)$ & 0.37 & 0.16 & 0.61 \\
\hline Fasting s-insulin $(\mathrm{pmol} / \mathrm{l})$ & $53.2(34.2)$ & $52.0(33.4)$ & $49.0(20.0)$ & 0.54 & 0.73 & 0.27 \\
\hline Fasting s-C-peptide (pmol/l) & $731(333)$ & $738(316)$ & $783(298)$ & 0.28 & 0.11 & 0.58 \\
\hline AUC $\mathrm{p}$-glucose $(\min \times \mathrm{mmol} / \mathrm{l})$ & $385(92)$ & $385(92)$ & $370(81)$ & 0.57 & 0.29 & 0.77 \\
\hline AUC s-insulin $(\min \times \mathrm{pmol} / \mathrm{l})$ & $33789(25664)$ & $33081(23425)$ & $31970(21187)$ & 0.92 & 0.73 & 0.77 \\
\hline AUC s-C-peptide $(\min \times \mathrm{pmol} / \mathrm{l})$ & $201157(70491)$ & $204696(70825)$ & $203595(66434)$ & 0.84 & 0.79 & 0.44 \\
\hline HOMA IR $(\mathrm{mmol} / \mathrm{l} \times \mathrm{pmol} / \mathrm{l})$ & $14.3(9.8)$ & $14.3(9.8)$ & $13.4(5.8)$ & 0.82 & 0.93 & 0.53 \\
\hline
\end{tabular}

Data are means (SD), unless otherwise stated. $p$ values were obtained using a general linear model (SPSS) with age and BMI as covariates, and sex and genotype as fixed factors on variables or transformed variables. AUC, incremental area

jects separately. However there was no difference between the different genotype groups (Tables 4 and 5 respectively). A combined analysis comprising all 5612 non-diabetic (NGT, IFG and IGT) subjects from the Inter99 study population also failed to show any phenotypic differences related to genotypes (data not shown). Unfortunately, information on size at birth of the subjects from the Inter99 study was not available. under the curve (0-120 min) during the OGTT; HOMA IR, HOMA insulin resistance; HOMA IS, HOMA insulin secretion; p-glucose, plasma glucose; s-C-peptide, serum C-peptide; s-insulin, serum insulin

A potential parent-of-origin effect of the class III allele was studied among NGT offspring, of whom one parent had Type 2 diabetes. Of 221 NGT offspring, 103 were class $I / I I I$ carriers and therefore informative with respect to determination of parental transmission of the class III allele. Of these, 32 offspring were found to have inherited a class III allele from their father and 31 to have inherited it from their 
Table 6. Clinical and biochemical data of 103 heterozygous carriers of the INS-VNTR class I/class III alleles (-23 HphI polymorphism) among NGT offspring of Caucasian Type 2 diabetic patients classified according to parental transmission of the class III allele

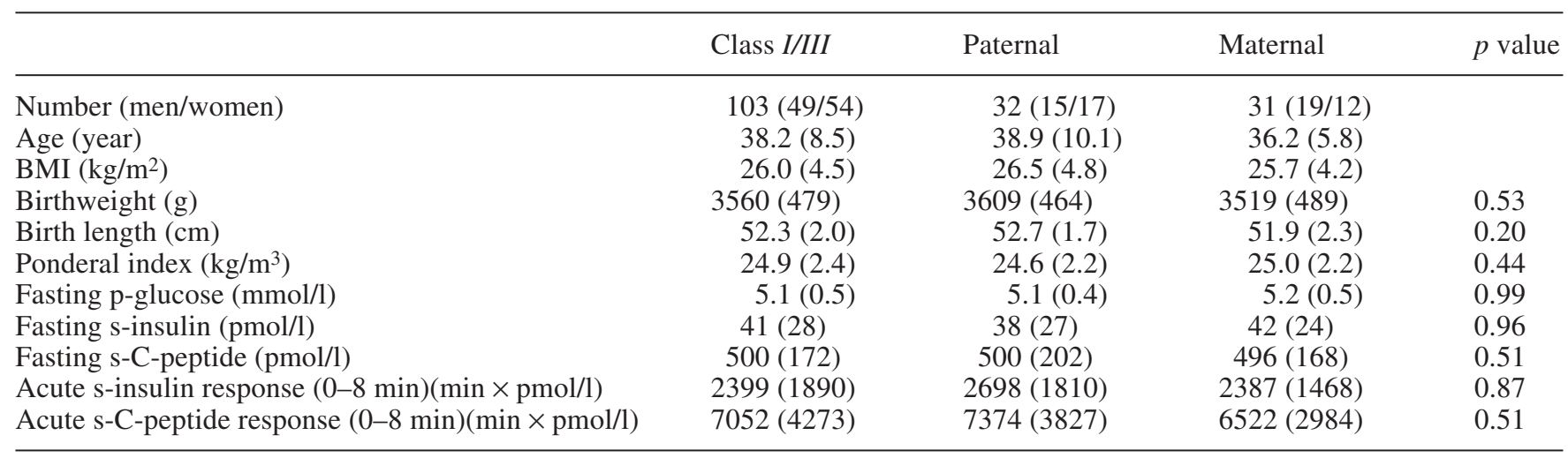

Data are means $(\mathrm{SD})$ unless otherwise stated. $p$ values were obtained by comparisons between subjects carrying one paternally transmitted class III allele (paternal) and subjects with one maternally transmitted class III allele (maternal). Analyses were done using a variance component model with genotype, sex, age and BMI as explanatory variables and family as a random factor. BMI and age were excluded from the model when analysing birth data. p-glucose, plasma glucose; s-C-peptide, serum C-peptide; s-insulin, serum insulin mother (total: $n=63$ ). No significant differences, either in size at birth or estimates of insulin release, were detected between class $I / I I I$ offspring with a paternally transmitted class III allele when compared to offspring with a maternally transmitted class III allele (Table 6).

\section{Discussion}

In contrast to the previously reported meta-analysis showing an association between the class III/III genotype of the INS-VNTR and Type 2 diabetes, we found no difference in frequency of the class III allele or in genotype distribution between Type 2 diabetic patients and NGT control subjects. The reason for the disparity is unknown, but the previously reported association could be a statistical type I error, since the results are based on a combined analysis of five small case-control studies (59 to 159 participants in each study, one study excluded from the combined analysis) [1]. In fact, the positive association is derived solely from a single study showing a strong association [21], whereas the remaining studies do not show significant associations between the class III/III genotype of the INS-VNTR and Type 2 diabetes. Furthermore, other studies have also examined a potential association between Type 2 diabetes and the class III allele, and even though one did report an association between Type 2 diabetes and paternally inherited class III alleles [10], these studies reported a lack of overall association between the INSVNTR class III allele and Type 2 diabetes [10, 13].

The genotype distribution among the Type 2 diabetic patients in the six studies from the meta-analysis was very different. The reason for this discrepancy is unclear, but it might be explained by ethnic differences. The genotype distribution among the Type 2 diabetic patients reported in the meta-analysis was also different from the genotype distribution observed in the present study (Fisher's exact test: $p=0.05$ ) [1]. As the present study includes a large number of individuals of ethnically homogenous origin, the estimated genotype distributions, both among Type 2 diabetic patients, and among NGT subjects, can be expected to reflect distribution of the class $I$ and class $I I I$ alleles in Danish Caucasians with considerable precision. Other studies with participants of Northern European origin have reported a genotype distribution similar to the one reported in the present study [2,3].

By performing a power calculation we demonstrated that in order to reproduce the difference in allelic frequency reported in the only study from the meta-analysis to show a positive association and to do this with a power of $95 \%$ and a significance level of $0.05,192$ individuals were required in each group. The present case-control study far exceeds this number of subjects.

Previous studies of genetic risk factors for the development of Type 2 diabetes with complex polygenic inheritance have shown that the effect of a single genetic variant, measured as relative risk, is likely to be in the range of 1.25 to 1.5 [22, 23, 24, 25]. In the present case-control study we have a high statistical power $(>95 \%)$ to detect a relative risk of 1.25 , and thus it seems unlikely that variation of the INS-VNTR as estimated by genotyping the $-23 H p h I$ SNP represents a major risk factor in the pathogenesis of Type 2 diabetes among Danish Caucasians.

The discrepancy between studies could also be related to the complex influence of the parent-of-origin effects on the INS-VNTR. The IGF-2 gene, which is located in the vicinity of the human INS gene, is imprinted and paternally expressed [26]. However, it is uncertain whether the human INS-VNTR region is imprinted. The murine insulin gene, Ins2, is paternally expressed in the yolk sac [27], and there is also 
evidence that this may be the case in the yolk sack of human embryos [28]. These results could suggest that the expression of the human INS gene is restricted to the paternal allele.

An effect of parent-of-origin of the INS-VNTR has been suggested in relation to Type 1 diabetes, in which a preferential transmission of the class $I$ allele from heterozygous class $I / I I I$ fathers to their diabetic offspring has been reported [1]. Another study showed an excess of paternal transmission of the class $I$ allele to obese children [29]. Concerning Type 2 diabetes, it was reported from a study examining 155 parent-offspring trios that the association between Type 2 diabetes and the INS-VNTR is mediated exclusively through the paternally transmitted class III allele [10]. However, the impact of imprinting on the INS-VNTR in relation to Type 2 diabetes has not yet been clarified, as a study of Pima Indians, also using parentoffspring trios, failed to demonstrate a clear parentof-origin effect on risk of Type 2 diabetes [13].

In the present study we did not have DNA from the parents of the case-control study, but we did examine for a potential parent-of-origin effect of the class III allele on pre-diabetic phenotypes among glucosetolerant offspring of a Type 2 diabetic parent. We were also unable to provide evidence for a parent-of-origin effect on the examined diabetes-related phenotypes. However, our study comprises only a limited number of subjects with information on parental transmission of the class III allele, and we only analysed prediabetic phenotypes. Thus, we cannot exclude a potential parent-of-origin effect on phenotypes related to Type 2 diabetes and on Type 2 diabetes susceptibility.

Additionally, it should be emphasised that genotyping the class $I$ and class $I I I$ alleles of the INS-VNTR is a rather broad classification of the very polymorphic region spanning the INS gene [19]. It has been reported that the association between the class $I$ allele and Type 1 diabetes is restricted to certain subclasses of the class $I$ allele [7]. Thus, the INS-VNTR class III might contain subclasses of tentative functional alleles that confer susceptibility towards Type 2 diabetes. Clearly, further studies are needed to elucidate this.

Conflicting data on the relationship between the $I N S$-VNTR and glucose-induced insulin release have also been reported. Several studies found no association between variation of the INS-VNTR and insulin secretion [30, 31, 32, 33]. In one study, insulin secretion was assessed during an IVGTT in 28 glucosetolerant subjects (14 class $I / I$ and 14 class $I I I / I I I$ carriers). Significant differences in oscillation activity between the two groups were detected [33]. However, no significant differences in total insulin release or firstphase insulin response were found, and the authors therefore concluded that the INS-VNTR does not play a major role in the control of insulin secretion. However, by examining 29 class $I / I, 29$ class $I / I I I$ and 6 class III/III carriers, a gene-dose-dependent effect of class III on 2-hour serum C-peptide levels during an OGTT was shown by Cocozza et al. [11]. This genedosage effect was also observed in a subpopulation examined with a hyperglycaemic clamp [11].

In the group of young healthy subjects we demonstrated that class III/III carriers, compared with class $I / I$ and class $I / I I I$ carriers, had significantly reduced acute serum insulin responses during an IVGTT. However, the class III/III carriers were also more insulin-sensitive, and analysis of the disposition index, which is an estimate of insulin secretion adjusted for insulin sensitivity, showed no significant decrease. A recent report demonstrated higher insulin secretion during an IVGTT among infants with the class III/III genotype. However, the class III/III carriers were more insulin-resistant, and increased insulin secretion might thus be a compensatory mechanism to insulin resistance [34]. The difference in beta cell response to an intravenous glucose load could also be due to the difference in age in the various study populations. The data might indicate that the insulin release associated with the class $I I I$ allele declines more rapidly with age than that associated with the class $I$ allele. Prospective data are needed to address this question.

With regard to BMI or decreased insulin sensitivity, we did not detect any significant effect of the class III allele on increased BMI or on decreased insulin sensitivity (estimated using the HOMA model), unlike a recently published study [3]. In our sample of young healthy subjects we measured the insulin sensitivity index $\left(S_{\mathrm{i}}\right)$ using an IVGTT in combination with an intravenous tolbutamide injection (the Minimal Model approach), and in fact we found a trend towards increased insulin sensitivity among the class III/III carriers. Among the 4444 middle-aged NGT subjects, 490 IFG subjects and 678 IGT subjects we observed (using the HOMA IR estimate) no difference in insulin sensitivity among carriers and non-carriers of the class III allele (when analysing both separately and in combination). In a combined analysis of three Caucasian study groups comprising a total of 1184 children and 1099 parents, Mitchell et al. reported that class III/III carriers had decreased insulin sensitivity (estimated using the HOMA model). However, a significant effect of the class III allele on insulin sensitivity was seen in only one of the examined study groups and in the combined analysis, and thus, as the authors conclude, this could be a chance finding from numerous statistical tests made in the study. In a study of obese children it was shown that the class $I$ allele was associated with increased fasting insulin levels, indicating increased insulin sensitivity among carriers of the class III allele [2]. Moreover, the INS-VNTR genotype was shown to have a strong influence on the correlation between insulin levels and BMI, indicating that a potential association between fasting insulin levels and the INS-VNTR depends on the degree of obesity. 
Among the 4444 middle-aged NGT subjects, we were unable to detect any significant effect of the INSVNTR class III allele on BMI or insulin release during an OGTT. The data from this group and the group of young healthy subjects are not directly comparable, as the effect of the class III allele among the young subjects was found after an intravenous glucose load, whereas the potential effect in middle-aged subjects was examined using an oral glucose load. It is possible, however, that the conflicting results from the group of young healthy subjects and the group of middle-aged NGT subjects is related to the difference in age. In a study of obese children, an association between the paternally inherited class $I$ allele and childhood obesity has been reported [29], and these results indicate that the effect of variation of the INS-VNTR could be dependent on age, and thus be more pronounced in young individuals.

We also analysed separately the potential influence of the class III allele in subjects with IFG and IGT. We did this to examine whether the effect of the class III allele was more pronounced in subjects at high risk of developing Type 2 diabetes [35, 36, 37]. However, among these "pre-diabetic" subjects, no significant effect of the class III allele on estimates of insulin release, BMI or insulin sensitivity was found.

The study of the 4444 NGT individuals may be the largest genotype-quantitative trait study so far made and is thus reasonably powered to evaluate the effect of the INS-VNTR on estimates of insulin release. Based upon the present findings, it seems unlikely that the class III allele estimated by genotyping the -23 $H p h I$ SNP has any consistent effect on insulin release during an OGTT among Danish Caucasians.

Finally, we did not observe any obvious association between the INS-VNTR class III allele and birth length, birthweight or ponderal index in young healthy subjects. Interestingly, the studies previously reporting associations between the class III allele and altered birthweight presented conflicting results. One study reported an association with increased birthweight $(\sim 250 \mathrm{~g})$ when considering non-changers (subjects with a small change in weight standard deviation score from birth to one year of age) [12], whereas another study demonstrated an association with a decreased birthweight ( 140 g) [13]. Moreover, a recent study also reported a lack of association between the class III allele and size at birth [3]. We were not able to distinguish between changers and non-changers, due to lack of early postnatal growth data. As birth data were not available, the relation between the class III allele and birthweight was not examined among the 4444 NGT subjects.

In conclusion, in the group of young healthy subjects carriers of the INS-VNTR class III/III had significantly decreased acute serum insulin and C-peptide responses during an IVGTT when compared with class $I / I$ and heterozygous carriers, indicating that variation of the INS-VNTR may have an impact on serum insulin and C-peptide responses in young individuals. However, no impact of the class III allele on serum insulin and C-peptide responses to an oral glucose load could be demonstrated in large-scale studies of middle-aged subjects. The INS-VNTR class III allele was not associated with Type 2 diabetes in a large case-control study.

Acknowledgements. This study was supported by grants from the Danish Medical Research Council (Growth and Regeneration), the Danish Diabetes Association, the Danish Research Academy, The Danish Heart Foundation, the Velux Foundation and the European Union (BMH4-CT98-3084). The authors wish to thank Helle Fjordvang, Annemette Forman, Lene Aabo, Bente Mottlau, Inge-Lise Wantzin, Marianne Stendal, Susanne Kjelberg, Jane Brønnum, Lis Ølholm, Maja Lis Halkjær and Quan Truong for technical assistance. We also thank Grete Lademann for secretarial support.

\section{References}

1. Bennett ST, Todd JA (1996) Human type 1 diabetes and the insulin gene: principles of mapping polygenes. Annu Rev Genet 30:343-370

2. Le Stunff C, Fallin D, Schork NJ, Bougneres P (2000) The insulin gene VNTR is associated with fasting insulin levels and development of juvenile obesity. Nat Genet 26:444446

3. Mitchell SMS, Hattersley AT, Knight B et al. (2004) Lack of support for a role of the insulin gene variable number of tandem repeats minisatellite (INS-VNTR) locus in fetal growth or Type 2 diabetes-related intermediate traits in United Kingdom populations. J Clin Endocrinol Metab 89:310-317

4. Lucassen AM, Screaton GR, Julier C, Elliott TJ, Lathrop M, Bell JI (1995) Regulation of insulin gene expression by the IDDM associated, insulin locus haplotype. Hum Mol Genet 4:501-506

5. Kennedy GC, German MS, Rutter WJ (1995) The minisatellite in the diabetes susceptibility locus IDDM2 regulates insulin transcription. Nat Genet 9:293-298

6. Vafiadis P, Bennett ST, Colle E, Grabs R, Goodyer CG, Polychronakos C (1996) Imprinted and genotype-specific expression of genes at the IDDM2 locus in pancreas and leucocytes. J Autoimmun 9:397-403

7. Bennett ST, Lucassen AM, Gough SC et al. (1995). Susceptibility to human type 1 diabetes at IDDM2 is determined by tandem repeat variation at the insulin gene minisatellite locus. Nat Genet 9:284-292

8. Paquette J, Giannoukakis N, Polychronakos C, Vafiadis P, Deal C (1998) The INS $5^{\prime}$ variable number of tandem repeats is associated with IGF2 expression in humans. J Bio Chem 273:14158-14164

9. Waterworth DM, Bennett ST, Gharani N et al. (1997) Linkage and association of insulin gene VNTR regulatory polymorphism with polycystic ovary syndrome. Lancet 349:986-990

10. Huxtable SJ, Saker PJ, Haddad L et al. (2000) Analysis of parent-offspring trios provides evidence for linkage and association between the insulin gene and type 2 diabetes mediated exclusively through paternally transmitted class III variable number tandem repeat alleles. Diabetes 49:126130 
11. Cocozza S, Riccardi G, Monticelli A et al. (1988) Polymorphism at the $5^{\prime}$ end flanking region of the insulin gene is associated with reduced insulin secretion in healthy individuals. Eur J Clin Invest 18:582-586

12. Dunger DB, Ong KKL, Huxtable SJ et al. (1998) Association of the INS VNTR with size at birth. Nat Genet 19:98-100

13. Lindsay RS, Hanson RL, Wiedrich C, Knowler WC, Bennett PH, Baier LJ (2003) The insulin gene variable number tandem repeat class I/III polymorphism is in linkage disequilibrium with birth weight but not type 2 diabetes in the Pima population. Diabetes 52:187-193

14. Hales CN, Barker DJP, Clark PMS et al (1991). Fetal and infant growth and impaired glucose tolerance at age 64 . BMJ 303:1019-1022

15. Drivsholm T, Ibsen H, Schroll M, Davidsen M, BorchJohnsen K (2001) Increasing prevalence of diabetes mellitus and impaired glucose tolerance among 60-year-old Danes. Diabet Med 18:126-132

16. Jørgensen T, Borch-Johnsen K, Thomsen TF, Ibsen H, Glümer C, Pisinger C (2003) A randomized non-pharmacological intervention study for prevention of ischaemic heart disease: baseline results Inter99 (1). Eur J Cardiovasc Prev Rehabil 10:377-386

17. Clausen JO, Borch-Johnsen K, Ibsen H et al. (1996) Insulin sensitivity index, acute insulin response, and glucose effectiveness in a population-based sample of 380 young healthy Caucasians. Analysis of the impact of gender, body fat, physical fitness, and life-style factors. J Clin Invest 98:1195-1209

18. Hansen T, Ambye L, Grarup N et al. (2001) Genetic variability of the $S U R 1$ promoter in relation to beta-cell function and Type II diabetes mellitus. Diabetologia 44:1330 1334

19. Stead JDH, Hurles ME, Jeffreys AJ (2003) Global haplotype diversity in the human insulin gene region. Genome Research 13:2101-2111

20. Buetow KH, Edmonson M, MacDonald R et al. (2001) High-throughput development and characterization of a genomewide collection of gene-based single nucleotide polymorphism markers by chip-based matrix-assisted laser desorption/ionization time-of-flight mass spectrometry. Proc Natl Acad Sci USA 98:581-584

21. Hitman GA, Jowett NI, Williams LG, Humphries S, Winter RM, Galton DJ (1984) Polymorphisms in the 5'-flanking region of the insulin gene and non-insulin-dependent diabetes. Clin Sci 66:383-388

22. Altshuler D, Hirschhorn JN, Klannemark M et al. (2000) The common PPAR gamma Pro12Ala polymorphism is associated with decreased risk of type 2 diabetes. Nat Genet 26:76-80

23. Jellema A, Zeegers MPA, Feskens EJM, Dagnelie PC, Mensink RP (2003) Gly972Arg variant in the insulin receptor substrate-1 gene and association with Type 2 diabetes: a meta-analysis of 27 studies. Diabetologia 46:990-995
24. Nielsen ED, Hansen L, Carstensen B et al. (2003) The E23K variant of Kir6.2 associates with impaired postOGTT serum insulin response and increased risk of type 2 diabetes. Diabetes 52:573-577

25. Weedon MN, Schwarz PEH, Horikawa Y et al. (2003) Meta-analysis and a large association study confirm a role for calpain-10 variation in type 2 diabetes susceptibility. Am J Hum Genet 73:1208-1212

26. Onyango P, Jiang S, Uejima H et al. (2002) Monoallelic expression and methylation of imprinted genes in human and mouse embryonic germ cell lineages. Proc Natl Acad Sci USA 99:10599-10604

27. Deltour L, Montagutelli X, Guenet JL, Jami J, Páldi A (1995) Tissue- and developmental stage-specific imprinting of the mouse proinsulin gene, Ins2. Dev Biol 168:686688

28. Moore GE, Abu-Amero SN, Bell G et al. (2001) Evidence that insulin is imprinted in the human yolk sac. Diabetes 50:199-203

29. Le Stunff C, Fallin D, Bougneres P (2001) Paternal transmission of the very common class I INS VNTR alleles predisposes to childhood obesity. Nat Genet 29:96-99

30. Permutt MA, Rotwein P, Andreone T, Ward WK, Porte D (1985) Islet beta-cell function and polymorphism in the 5 -flanking region of the human insulin gene. Diabetes 34:311-314

31. Sten-Linder M, Wedell A, Iselius L, Efendic S, Luft R, Luthman H (1993) DNA polymorphisms in the human tyrosine hydroxylase/insulin/insulin-like growth factor II chromosomal region in relation to glucose and insulin responses. Diabetologia 36:25-32

32. Owerbach D, Bell GI, Rutter WJ, Shows TB (1980) The insulin gene is located on chromosome 11 in humans. Nature 286:82-84

33. Ahmed S, Bennett ST, Huxtable SJ, Todd JA, Matthews DR, Gough SC (1999) INS VNTR allelic variation and dynamic insulin secretion in healthy adult non-diabetic Caucasian subjects. Diabet Med 16:910-917

34. Bazaes RA, Petry CJ, Ong KK, Avila A, Dunger DB, Mericq MV (2003) Insulin gene VNTR genotype is associated with insulin sensitivity and secretion in infancy. Clin Endocrinol 59:599-603

35. The DECODE study group on behalf of the European Diabetes Epidemiology Group (1999) Glucose tolerance and mortality: comparison of WHO and American Diabetes Association diagnostic criteria. Lancet 354:617621

36. Larsson H, Berglund G, Lindgärde F, Ahrén B (1998) Comparison of ADA and WHO criteria for diagnosis of diabetes and glucose intolerance. Diabetologia 41:11241125

37. Shaw JE, Zimmet PZ, de Courten M et al. (1999) Impaired fasting glucose or impaired glucose tolerance: What best predicts future diabetes in Mauritius? Diabetes Care 22:399-402 